\title{
Commentary: Knowing when we are doing harm: Is glial fibrillary acidic protein a game changer?
}

\author{
David M. Overman, MD
}

\author{
From the Division of Cardiac Surgery, The Children's Heart Clinic, Division of Cardiovascular Surgery, Chil- \\ dren's Hospitals and Clinics of Minnesota, Minneapolis, Minn. \\ Disclosures: Author has nothing to disclose with regard to commercial support. \\ Received for publication Feb 15, 2019; accepted for publication Feb 18, 2019. \\ Address for reprints: David M. Overman, MD, The Children's Heart Clinic, 2530 Chicago Ave S, Suite 500, Min- \\ neapolis, MN 55404 (E-mail: doverman@chc-pa.org). \\ J Thorac Cardiovasc Surg 2019;157:2003-4 \\ $0022-5223 / \$ 36.00$ \\ Copyright (c) 2019 by The American Association for Thoracic Surgery \\ https://doi.org/10.1016/j.jtcvs.2019.02.075
}

Primum non nocere.

-Unknown

It's not what you don't know that gets you into trouble. It's what you know for sure that just ain't so. -Unknown (often attributed to Mark Twain)

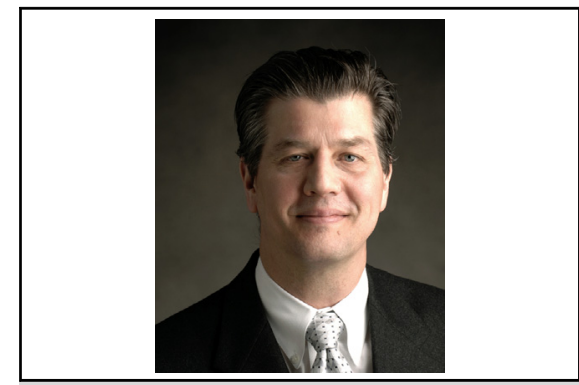

David M. Overman, MD

Central Message

A real-time measure of cerebral injury that is correlated with neurodevelopmental outcome is a potential game changer.

See Article page 1996.
It has become an almost pedestrian observation that the tremendous progress in the field of congenital heart surgery has driven us beyond mortality as a meaningful measure of success and that attention is increasingly focused on addressing the many observed morbidities associated with these interventions. Although that point of view might be characterized as a bit rose-colored, it is uncontestable that neurodevelopmental impairment, in particular, dominates the landscape of the community of survivors with congenital heart disease. The origins of this phenomenon are myriad, and our understanding of them rudimentary. They may be genetically programmed or influenced, the product of in utero physiology resulting in dysmaturation ("encephalopathy of congenital heart disease"), or they may be the sequelae of postnatally disadvantaged physiologies, such as cyanosis or subnormal cardiac output. They may also be a result of complications related to our therapeutic interventions. These "sins of commission" are often painfully obvious (seizures, ischemic encephalopathy after cardiac arrest, or embolic stroke, for instance), but they may also be quite subtle or even silent, becoming manifest only as time passes.

It is this last category of etiology that appropriately demands our collective attention. Some of the best science in our field's short history investigates associations between clinical practice or patient factors and neurodevelopmental outcome. ${ }^{1-8}$ An abridged list of targets of inquiry includes circulatory arrest or cardiopulmonary bypass time, $\mathrm{pH}$ management technique, hematocrit, volatile anesthetics, blood glucose, thyroid hormone, perioperative events, and length of hospital stay. These studies all share a common structure. That is, they prospectively or retrospectively "isolate" (not truly possible, of course) a variable of interest and measure neurodevelopmental outcomes (with a variety of methods) some time later. A portion of each article is spent addressing potential confounders (and there are many) in the connection between the variable of interest and imperfect neurodevelopmental outcome measures. It is a time-consuming, difficult undertaking that leaves a residue of doubt about the importance of whatever the variable of interest is in the resulting neurodevelopmental outcome, no matter how good the statistical analysis may be. A direct, simple, and reliable measure of brain injury that is known to be correlated with neurodevelopmental outcome could have a powerful and immediate effect on our ability to investigate questions regarding therapeutic interventions and late neurodevelopmental outcomes.

The study by Graham and colleagues ${ }^{9}$ in this month's Journal explores the notion that perioperative glial fibrillary acidic protein (GFAP) levels may be useful as indicators of the likelihood of late neurodevelopmental impairment. Recently, in a smaller prospective single-center study, Vedovelli and colleagues ${ }^{10}$ demonstrated an association between GFAP levels and neurodevelopmental outcomes The current study of Graham and colleagues ${ }^{9}$ is a secondary analysis of neonates from 2 institutions participating in a recently completed prospective randomized trial of corticosteroids in neonates undergoing cardiopulmonary bypass, and the findings are quite compelling. 
After controlling for several variables, GFAP levels were independently associated with motor composite scores on the Bayley Scales of Infant and Toddler Development, Third Edition. That is notable enough. What is most remarkable about this report, however, is what Graham and colleagues ${ }^{9}$ found regarding center-specific data. One institution (site 1) had median GFAP levels double those of the other institution (site 2) at the cessation of bypass, when GFAP levels were highest, and site 1 patients had significantly lower cognitive, language, and motor composite scores on the Bayley Scales of Infant and Toddler Development at 1 year than those at site 2 .

There are, of course, many potential confounders to this finding. There were, for instance, differences in patient variables by site ( $91 \%$ of patients were white at site 1 vs $61 \%$ at site 2; site 1 patients were younger by 2 days on average). Nevertheless, the conduct of cardiopulmonary bypass at each institution, although somewhat different, would be considered quite reasonable by nearly all congenital surgeons. Ironically, the site with lower Bayley Scales of Infant and Toddler Development scores was also the site with significantly shorter pump times. The implication is that there is a feature of what we would all identify as conventional intraoperative management that results in more acute neurologic injury and more neurodevelopmental impairment a year later. That is a powerful and sobering finding.

The injunction to "first do no harm" is widely attributed to Hippocrates and is assumed by many to be in the Hippocratic oath. Both notions are incorrect. While certainly a laudable principle, the origins of the phrase most likely date to mid-19th century England's medical teaching and literature. ${ }^{11}$ The second familiar adage is often and incorrectly credited to Mark Twain (its origins are obscure, and the saying had many iterations over time, being linked to several different authors and humorists). ${ }^{12}$ Both of these inaccurate attributions are examples of how easy it is. The ironic content of the second only drives home the point.

When cardiac surgery was in its infancy, it was universally recognized as a dangerous undertaking. Lower mortality in the present era notwithstanding, our undertaking is still a dangerous one. That hazard now resides in the domain of lifelong disability as a result of practices that are injurious to the human brain, whether we know them to be so or not. The work of Graham and colleagues ${ }^{9}$ represents the best qualities of clinical science: an important question, a simple design, straightforward measures, and transparent non-egoistic reporting of results. We should applaud these attributes. Perhaps the introduction of a real-time measure of cerebral injury will help us uncover practices that, in fact, silently harm.

\section{References}

1. Jonas RA, Bellinger DC, Rappaport LA, Wernovsky G, Hickey PR, Farrell DM, et al. Relation of $\mathrm{pH}$ strategy and developmental outcome after hypothermic circulatory arrest. J Thorac Cardiovasc Surg. 1993;106:362-8.

2. Wypij D, Newburger JW, Rappaport LA, duPlessis AJ, Jonas RA, Wernovsky G, et al. The effect of duration of deep hypothermic circulatory arrest in infant heart surgery on late neurodevelopment: the Boston circulatory arrest trial. J Thorac Cardiovasc Surg. 2003;126:1397-403.

3. Gaynor JW, Nicolson SC, Jarvik GP, Wernovsky G, Montenegro LM, Burnham NB, et al. Increasing duration of deep hypothermic circulatory arrest is associated with an increased incidence of postoperative electroencephalographic seizures. J Thorac Cardiovasc Surg. 2005;130:1278-86.

4. Newburger JW, Jonas RA, Soul J, Kussman BD, Bellinger DC, Laussen PC, et al Randomized trial of hematocrit $25 \%$ versus $35 \%$ during hypothermic cardiopulmonary bypass in infant heart surgery. J Thorac Cardiovasc Surg. 2008;135 347-54. 354.e1-4.

5. von Rhein M, Dimitropoulos A, Valsangiacomo Buechel ER, Landolt MA, Latal B. Risk factors for neurodevelopmental impairments in school-age children after cardiac surgery with full-flow cardiopulmonary bypass. $J$ Thorac Cardiovasc Surg. 2012;144:577-83.

6. Gaynor JW, Kim DS, Arrington CB, Atz AM, Bellinger DC, Burt AA, et al. Validation of association of the apolipoprotein E $\varepsilon 2$ allele with neurodevelopmental dysfunction after cardiac surgery in neonates and infants. J Thorac Cardiovasc Surg. 2014;148:2560-6.

7. Mittnacht J, Choukair D, Kneppo C, Brunner R, Parzer P, Gorenflo M, et al. Long-term neurodevelopmental outcome of children treated with triiodothyronine after cardiac surgery: follow-up of a double-blind, randomized, placebo-controlled study. Horm Res Paediatr. 2015;84:130-6.

8. Diaz LK, Gaynor JW, Koh SJ, Ittenbach RF, Gerdes M, Bernbaum JC, et al. Increasing cumulative exposure to volatile anesthetic agents is associated with poorer neurodevelopmental outcomes in children with hypoplastic left heart syndrome. J Thorac Cardiovasc Surg. 2016;152:482-9.

9. Graham EM, Martin RH, Atz AM, Hamlin-Smith K, Kavarana MN, Bradley SM, et al. Association of intraoperative circulating-brain injury biomarker and neurodevelopmental outcomes at 1 year among neonates who have undergone cardiac surgery. J Thorac Cardiovasc Surg. 2019;157:1996-2002.

10. Vedovelli L, Padalino M, Suppiej A, Sartori S, Falasco G, Simonato M, et al. Cardiopulmonary-bypass glial fibrillary acidic protein correlates with neurocognitive skills. Ann Thorac Surg. 2018;106:792-8.

11. Smith CM. Origins and uses of primum non nocere — above all do no harm! J Clin Pharmacol. 2005;45:371-7.

12. Seybold M. The apocryphal Twain: "Things we know just ain't so." October 6, 2016. Available at: https://marktwainstudies.com. Accessed March 27, 2019. 